
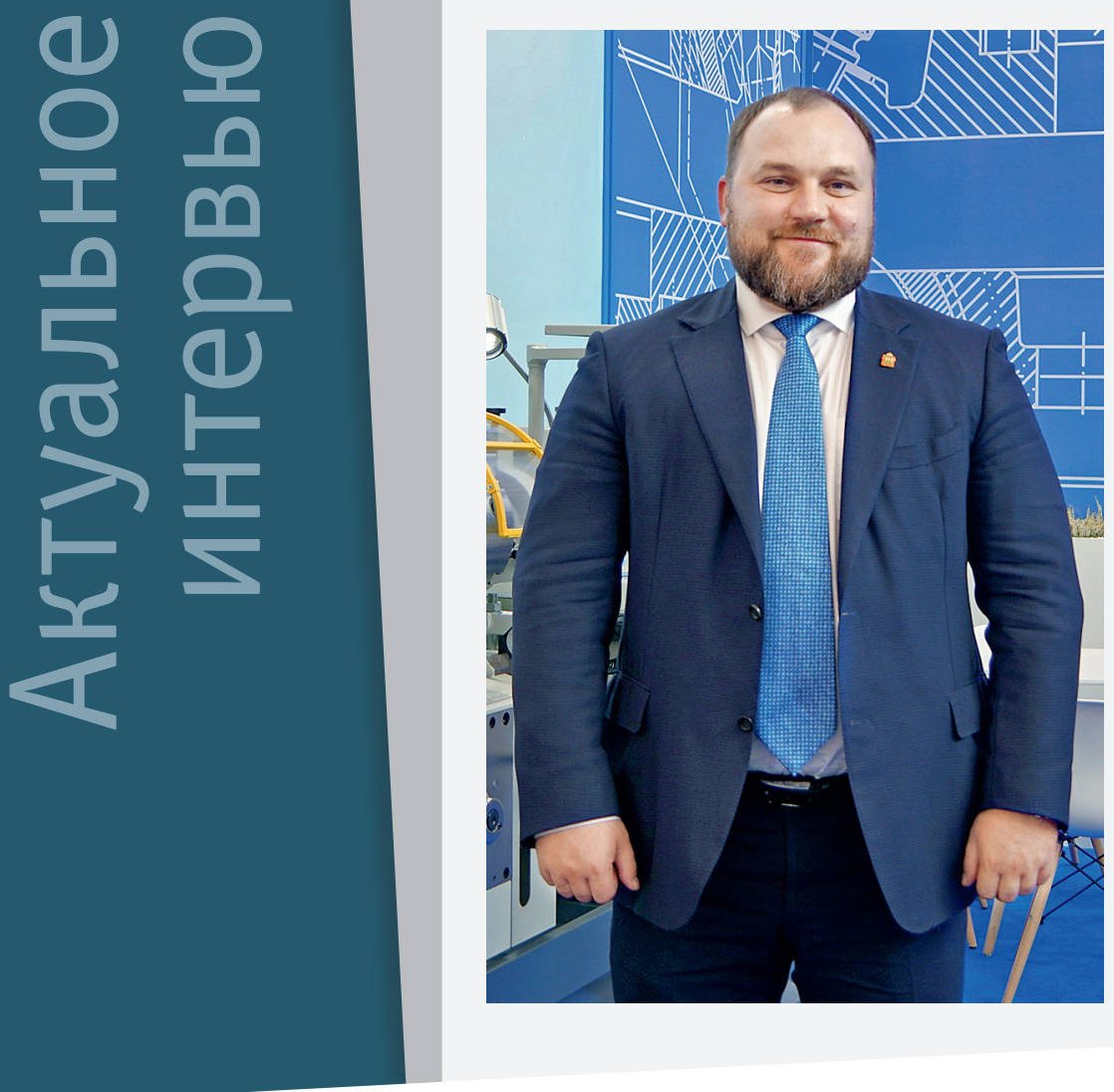

Предыдущий разговор с генеральным директором компании «СтанкоМашСтрой» Олегом Александровичем Кочетковым на выставке ЕМ0 состоялся в 2017 году, когда компания впервые приняла участие в крупнейшем станкостроительном форуме и представила свою продукцию зарубежным потребителям. За прошедшие два года «СтанкоМашСтрой» значительно расширил производство, закрепился на внешних рынках, повысил качество и уровень оснащения своей продукции. 06 изменениях, произошедших в компании за это время, о планах на будущее корреспондент журнала побеседовал с Олегом Александровичем на стенде предприятия уже на выставке ЕMO 2019.

\title{
«СтанкоМашСтрой» ОСВАИВАЕТ ЭКСПОРТНЫЕ РЫНКИ
}

- За Время, которое прошло с нашей последней встречи, какие изменения произошли В компании, как она разЗиВается?

- Первая выставка ЕМО, которая состоялась в 2017 году, показала наши сильные и слабые стороны. На основании анализа этого опыта, мы приняли решение по какому пути нам развиваться дальше. Это касается номенклатуры станков, которые мы поставляем и на российский рынок, и на экспорт. Некоторые компании считают, что на экспорт нужно делать лучше, а на внутренний рынок «и так сойдет», мы же исходим из того, что и экспортная продукция, и продукция для внутреннего рынка должны иметь одинаковое качество.

Естественно, экспортный покупатель определяет тренды модернизации, оснащения, улучшения качества. За последние два года мы реализовали экспортные поставки в девять стран: это Латвия, Литва, Монголия, Казахстан, Узбекистан, Ирландия, Венгрия, Германия и Швейцария.
- Bы считаете, что на это повлияло Ваше участие В прошлой Выстаßке?

- Да, в том числе и выставка оказала положительное влияние. Мы нашли для себя определенную нишу, как и в 2017 году, мы реализовали те станки, которые привезли на выставку. То есть, как и в прошлый раз, мы будем возвращаться с выставки налегке.

Лидирующие позиции в нашем экспорте занимает Германия. В 2018 году мы реализовали в этой стране 12 станков, а за этот неполный год продаем уже восьмой станок. Мы улучшаем свои позиции на рынке, постоянно совершенствуемся и, соответственно, увеличиваем объем продаж. В этом году, по моим оценкам, в Германию мы поставим уже 18 станков и постараемся обеспечить прирост в следующие годы. Доля экспорта стала для нас очень важна, мы поставили цель довести ее до 50\% от общего объема производства. Это возможно, хотя на достижение этой цели понадобится не один год. Сердца европейских потребителей растопить сложно. Присутствует некоторое недоверие к нашей про- 


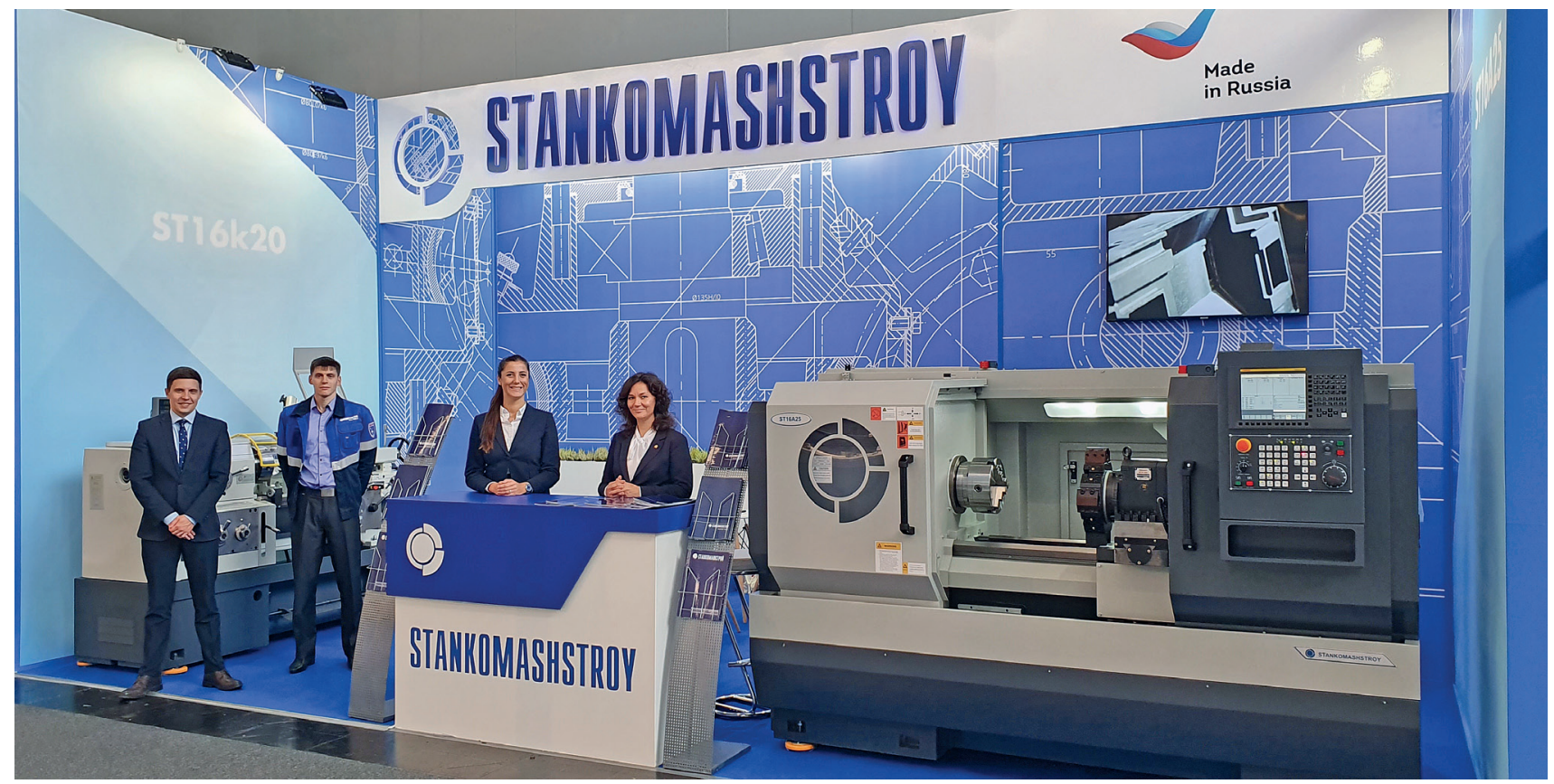

дукции, мы стараемся год от года его искоренять. И это неплохо получается.

- В прошлый раз Вы говорили о том, что планируете открыть В Германии серВисный центр.

- Мы долго думали по поводу сервисного центра и сейчас видим, что легко получить визу для нашего работника, у каждого из нас есть либо годовая виза, либо шенгенская на два-три года, цена билета любыми авиалиниями в одну сторону составляет 7-8 тыс. руб., это гораздо интереснее, чем на постоянной основе отправлять нашего сотрудника за рубеж. Для наших работников командировка в Европу рассматривается как некая премия, они всегда на это готовы, кроме того происходит обмен знаниями в области культуры производства. По этим причинам и при существующем объеме поставок сервисный центр в Европе пока не требуется.

Поломки оборудования и нарекания на качество его работы сведены к минимуму, за два года наши специалисты выезжали всего четыре раза. Когда мы перешагнем отметку в 100 единиц поставляемого оборудования, тогда ситуация с целесообразностью собственного сервисного центра изменится.

Сейчас для нас открывается новый рынок - это США. В прошлом году мы довольно успешно приняли участие в выставке в Чикаго, хотя, как правило, на американском рынке есть свои нюансы, но сейчас мы нашли дилера, ведем с ним плотные переговоры, и я думаю, что на следующий год мы закрепимся и на американском рынке.

Сегодня у нас запланирована встреча с президентом японской компании Fanuk, поскольку на наши станки мы устанавливаем систему ЧПу Fanuk.
На этой встрече мы планируем договориться о поставках наших станков в Японию. В этом нас поддерживает и президент Ассоциации «Станкоинструмент» Г.В. Самодуров. Нужно активнее выходить на внешние рынки, занимать более жесткую переговорную позицию.

Отдельную благодарность хочется высказать Российскому экспортному центру. По итогам 2017 года мы получили компенсацию затрат на проведение выставок, она была довольно существенной. Нам очень приятно, что государство поддерживает нас и заботится о продвижении продукции высоких переделов. Это позволяет нам наращивать компетенции и технологический потенциал.

Мы видим результат этих мер поддержки - по сравнению с 2017 годом на выставке ЕМО стало больше российских экспонентов и больше посетителей из России.

- Получается даже так, что у экспонентов из России больше российских посетителей, чем на российских выставках?

- Об этом и речь. Но я хочу особо подчеркнуть, что к поставкам станков за рубеж нужен особый подход. Поставки на экспорт - дело очень сложное, и не каждая компания к этому готова, потому что продажи в России осуществлять гораздо легче. Но здесь мы говорим о перспективе, о будущем, это долгая история, возможно на десятилетия. Но, если компания хочет развиваться, задумывается о своем будущем, она должна выходить на экспорт.

- «СтанкоМашСтрой» - это частная компания?

- Да, я являюсь единственным собственником и генеральным директором компании. 


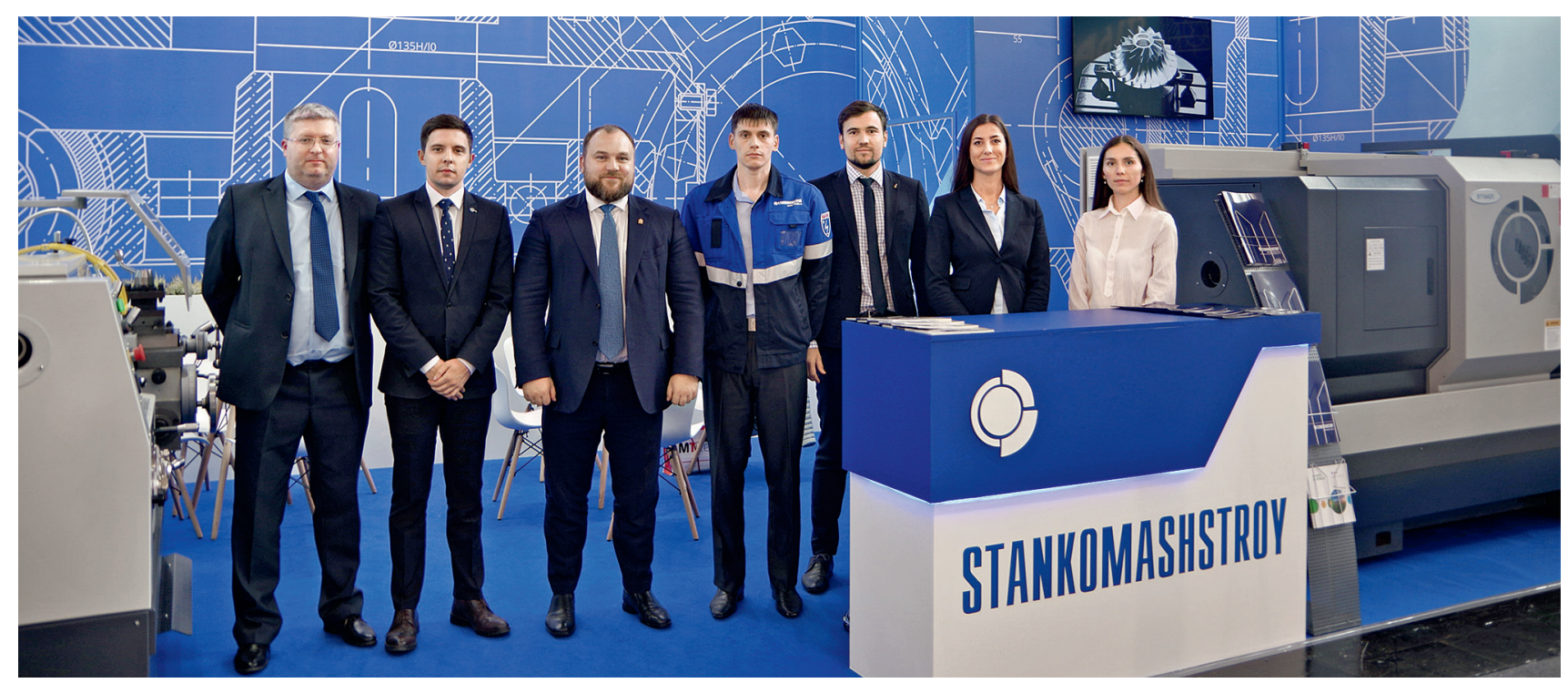

- Государство никак не участвует в компании?

- Пока нет. Никакой доли государства у нас нет. Мы полностью частная компания. Безусловно, есть определенная поддержка со стороны государства, сейчас мы рассматриваем ряд инструментов, в ряде программ мы собираемся участвовать, поскольку считаем их необходимыми для развития компании. Мне кажется, что в настоящее время создана хорошая почва для взращивания таких компаний, как наша. К сожалению, я хотел бы отметить, что государственная поддержка носит несколько однобокий характер. Государство всегда перестраховывается от потерь. Мы не разделяем между собой риски.

Мы платим налоги в полном объеме, создаем рабочие места, высокотехнологичные, с высокой средней заработной платой, приобретаем оборудование, получаем компетенции - обучаем персонал за рубежом. То есть делаем для государства гораздо больше, чем получаем взамен. Я не говорю о том, что нам нужно снизить налоги или создать рыночные преференции, но поддержка экспорта нам нужна.

Например, выставка в Чикаго в прошлом году обошлась нам в 8 млн руб. Это была вылазка на совершенно неподготовленный рынок. Нас там никто не знал, у нас не было предварительных контактов. Для американцев шоком было уже то, что в России есть станкостроение. Мы надеемся, что если в следующем году мы снова поедем в Чикаго, Российский экспортный центр обратит на это внимание и поможет нам в продвижении нашей продукции. Со своей стороны мы проделали большую переговорную работу, в частности, наши американские коллеги приезжали и сюда, на ЕMO. Мы обсуждали различные ценовые аспекты, проблемы постоплаты, что на рынке станкостроения является нормой. Государство также должно это учитывать, в частности, при взимании НДС с полной суммы контракта.
- А чем привлекает немиев и американиев, у которых собственная мощная индустрия, ваша продукция?

- Основные привлекательные стороны нашей продукции - это простота, надежность и соответствующая цена. Когда мы принимаем во внимание ценовую политику наших конкурентов из различных стран, то они нам начинают проигрывать. Кроме того, надо учитывать постоянно происходящие торговые войны между разными странами. Сейчас, в частности, идет торговая война между Южной Кореей и Японией, между Китаем и США - на китайские станки установлена заградительная пошлина в размере $29 \%$. Это дает нам определенные шансы.

Конечно, нам было бы проще не искать конечного покупателя в каждой стране, а открывать свои представительства с шоу-румами, складами, но это требует большого количества свободных денег. И желательно не заемных, поскольку ставка по кредиту $10 \%$ на рынке станкостроения сейчас практически не перекрывается. Станкостроение - это не та отрасль, в которой реализуются высокомаржинальные проекты. Здесь необходимо работать постоянно с большим объемом продукции, с большим переделом, с высокой долей кооперации, желательно - внутренней, и с большими капиталовложениями. Высокая конкуренция не дает возможности заложить в цену продукции не только все издержки, но и средства для будущего развития.

\section{- Ваше производство уже стало серийным?}

- Да, мы уже три года находимся в стадии серийного производства, в прошлом году произвели 252 станка, из которых 30 экспортировали. В этом году мы повысили уровень локализации, поскольку, в соответствии с Постановлением Правительства № 719 , в 2020 году станок будет считаться российским, если уровень локализации будет не ниже $70 \%$. В данный 
момент этот показатель составляет 50\%, поэтому пришлось часть комплектующих дорабатывать, что увеличило финансовые вложения и повлекло некоторые ценовые изменения в сторону повышения. Это привело к тому, что некоторые покупатели от нас ушли в более дешевый сегмент.

Можно привести много примеров, когда на российском рынке китайский станок стоит 2,7 млн руб., а наш станок - более технически оснащенный, более мощный, тяжелее на 1 т, с системой ЧПУ - стоит лишь на 10\% дороже. Но потребитель все равно выбирает дешевый продукт. Почему наш покупатель принимает такое решение? Возможно, это является следствием того, что денег на рынке явно недостаточно. Ведь качество китайской продукции не всегда удовлетворительно. Вот и на выставке ЕМО мы видим снижение количества китайских участников, Европа не готова покупать в больших объемах китайскую продукцию.

\section{- В этом году Вы представляете на Выставке новую модель?}

- Нет, это уже существующая модель, но мы ее доработали, улучшили, пришли к более оптимальному соотношению цена/качество, увеличили степень локализации. На этом станке мы сделали люнеты, патрон, фартук, суппорт, резцедержатель, заднюю бабку и станину - это собственное производство, а не локализация. За счет этого степень локализации возросла до 70\%. Этот станок мы демонстрировали и на Петербургском экономическом форуме, когда наш стенд посещали Дмитрий Рогозин, Максим Орешкин и Сергей Глазьев. Мы рассказывали о развитии станкостроения в Пензенской области, которая в советские времена не считалась станкостроительным регионом. То есть мы не говорим о каком-либо восстановлении - это новая отрасль для экономики Пензенской области. Мы вовлекли много компаний региона в кооперацию, сейчас они производят комплектующие, например конвейеры для удаления стружки, не только для нас, но и для станкостроителей России и других стран.

\section{- Что Вы могли бы сказать о ситуации на россий- ском рынке?}

- В данный момент российский рынок немного стагнирует. Промышленность испытывает некоторые затруднения с ростом, выручка либо стабильна, либо наблюдается некоторый спад. Предприятия не спешат переоснащаться, модернизировать свои производства. Уже второй год подряд мы наблюдаем падение рынка примерно на 5\% в год. Это некритично и воспринимается совершенно нормально, есть пример южнокорейского рынка, который падал на 30-40\% в год. Мы понимаем, что наши пять процентов снижения - это отложенный спрос, ситуация рано или поздно поменяется к лучшему, и те объемы, которые мы сейчас теряем, вернутся ростом рынка. Примером тому была и ситуация на рынке в 2008-2009 годах, когда был спад, а в 2010-2011 годах был огромный рост. То же самое должно произойти и сейчас. 2020 год будет, скорее всего, еще более тяжелым, но в 2021-2022 годах ситуация сильно изменится. На это будут влиять в том числе и национальные проекты, в экономику будут влиты значительные денежные средства, которые дойдут до каждого.

\section{- Каковы Ваши планы на ближайшее будущее?}

- Нельзя сказать, что планов у нас «громадье», это вполне нормальные планы - в августе этого года мы открыли второй производственный цех, заложили капсулу в фундамент третьего цеха, это цех мехобработки, строительство которого должно закончиться в этом году. Также мы сейчас покупаем участок земли площадью 0,5 га, в следующем году будем строить там четвертый цех. Степень локализации и кооперации с российскими компаниями планируем наращивать, но хотелось бы делать это с партнерами, которые выполняли бы функционал по качеству, срокам и цене.

Не всегда мы видим адекватную оценку своих возможностей, иногда компания может что-то делать, но не готова делать это по рыночной цене, а только выше ее. Сотрудничество с такими компаниями невозможно, поскольку, в конечном итоге, мы станем неконкурентоспособны. Иногда партнеры срывают сроки, не дают требуемого качества, приходится долю кооперации снижать и делать часть комплектующих самим. Надеемся, что ситуация будет меняться в лучшую сторону.

В частности, сейчас есть проблема с российскими двигателями. Нас приглашают на некоторые заводы, мы ведем переговоры, ищем пути их поддержки. Но если собственник принимает решение о закрытии производства, мы, естественно, повлиять на ситуацию не можем. И на эту проблему должно обратить внимание уже государство. Промышленным предприятиям сложно выживать в условиях конкуренции с импортом. Речь не идет об установлении заградительных пошлин, но при прочих равных следует иметь в виду, что зарубежные производители при поставках в Россию поддерживают своих покупателей. Они привлекают и государственные инструменты своих стран, и банки, которые предоставляют заемные средства под низкий процент. Выходя на зарубежные рынки, мы тем же самым похвастаться не можем.

Тем не менее я полагаю, что цель, которую я установил для себя и компании, - производить тысячу станков в год - достижима. Достигнем мы этого, по прогнозам, в 2023 году или чуть позже, это уменьшит себестоимость, стоимость покупных комплектующих, то есть повысит конкурентоспособность нашей продукции.

Беседовала О. Лаврентьева 